\title{
Evolution of the Pakistan Space Weather Centre (PSWC)
}

\author{
Afnan Tahir, Muhammad Ayyaz Ameen, Madeeha Talha, Ghulam Murtaza, Muneeza Salman Ali, and \\ Gohar Ali
}

Pakistan Space and Upper Atmosphere Research Commission (SUPARCO), Karachi, Pakistan

Correspondence: Afnan Tahir (afnan.tahir27@gmail.com)

Received: 13 December 2019 - Accepted: 26 April 2020 - Published: 5 June 2020

\begin{abstract}
This work focuses on the progress of space weather monitoring in Pakistan. Pakistan's first geomagnetic observatory was established in Quetta in 1953. However, the beginning of what we would now call space weather services on a formal level took place in 1971, when the national space agency, the Pakistan Space and Upper Atmosphere Research Commission (SUPARCO), established the country's first ionospheric station. Later, in 1983, a geomagnetic observatory was set up in Karachi with the aim of providing high frequency (HF) support and geomagnetic storm alerts to relevant users. With the progression of time, nations began to prioritize space weather monitoring to ensure the safety and security of technological assets. Therefore, it was considered imperative to upgrade the array of instruments in order to maintain the reliability of operations and the efficient utilization of data to contribute to research at local, regional and global scales. Pakistan has recently established a dedicated space weather monitoring facility known as the Pakistan Space Weather Centre (PSWC). This paper describes the historic evolution of space weather infrastructure in Pakistan and the current contribution of the PSWC.
\end{abstract}

\section{Introduction}

The history of geophysical monitoring in Pakistan dates back to 1953 with the establishment of the first geomagnetic observatory in Quetta. The Pakistan Meteorological Department (PMD) laid the foundation for geomagnetic studies and contributed data internationally during the International Geophysical Year (IGY) campaign from 1957 to 1958 (Nicolet, 1957). The instrument, received from the British Geological Survey (BGS), had the capability of recording $D, H$ and $Z$ components. IGY proved to be a remarkable initiative to integrate meteorological and solar data on a global scale. This activity enabled countries like Pakistan to pursue a space science programme thereafter. In 1961, the foundation for the national space agency - the Pakistan Space and Upper Atmosphere Research Commission (SUPARCO) was laid (Mehmud, 1989). Similarly, in 1961, a geomagnetic observatory was set up in Gilgit by PMD with assistance from BGS to monitor geomagnetic variations in the northern region of Pakistan. Considering the importance of high frequency (HF) support for radio communication, an ionospheric station was established in Karachi in 1971. This development enabled the creation of the Ionospheric Research
(IR) Division at SUPARCO. The ionospheric data acquired were further disseminated to national users. Later, the ionospheric and geomagnetic network was upgraded with the aim of increasing research and data sharing with the international community, and the IR Division was officially renamed the Space Weather Monitoring (SWM) Division in 2012. Figure 1 shows the geographical locations of the previous and current observatories in Pakistan.

This article documents the development and history of ionospheric and geomagnetic monitoring in Pakistan, the transition into the Pakistan Space Weather Centre (PSWC) and other recent developments.

\section{Historical perspective of ionospheric and geomagnetic monitoring in Pakistan}

Pakistan initiated geomagnetic monitoring within a decade of political independence in 1947. The participation and contribution of data globally during IGY opened new paths for geomagnetic research in Pakistan, as it helped to establish good connections with the international scientific community. By 1961, Pakistan had a dedicated national space agency with 


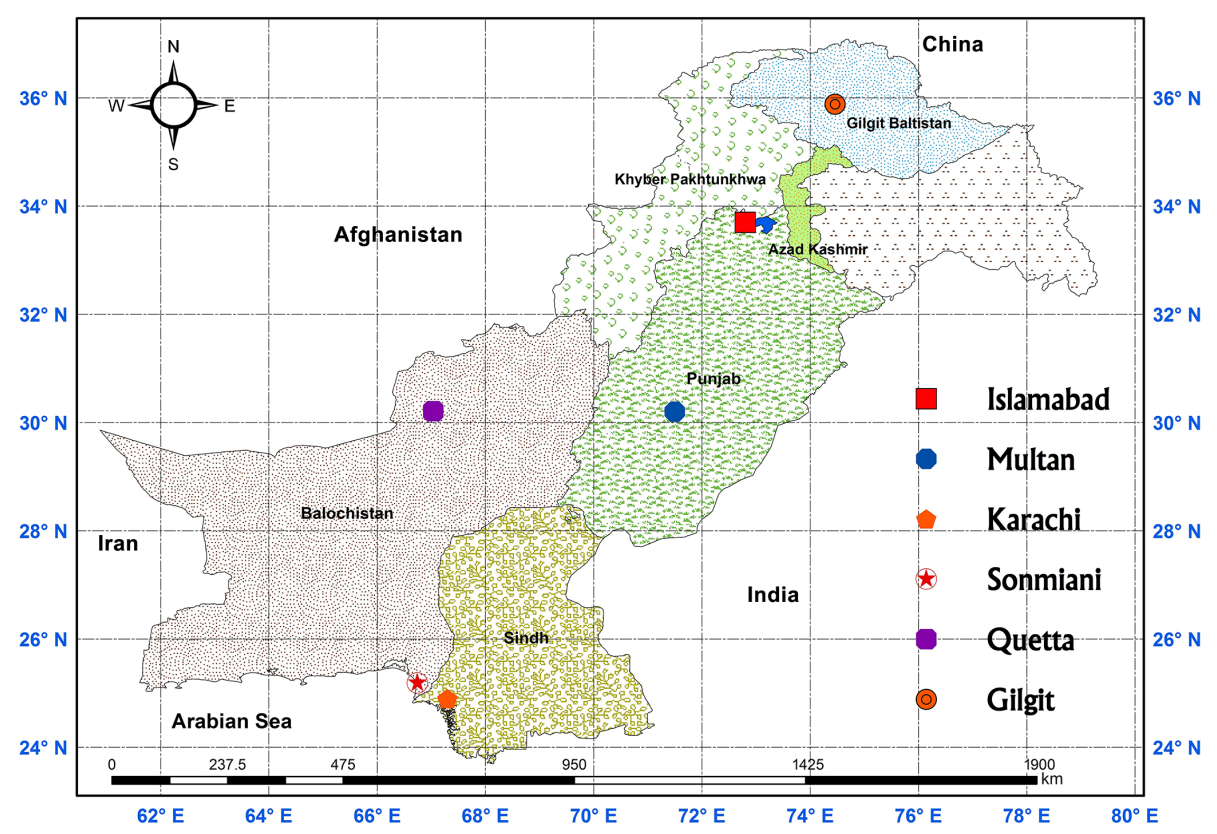

Figure 1. Geographical locations of ionospheric and geomagnetic observatories in Pakistan.

a vision to establish a strong geophysical observing network in the country. The chronology of the expansion of the ionospheric and geomagnetic observing network in Pakistan is presented in Table 1 .

Pakistan's first ionosonde, Mark II (a British ionosonde), was installed in Karachi in 1971. It was replaced by the Japanese PIR-9 (Panoramic Ionospheric Recorder-9; Fig. 2) ionosonde after 4 years. The Karachi ionospheric station covered the southern part of Pakistan, and it was considered feasible to establish an ionospheric observatory in the northern region. Thus, aiming to achieve coverage of northern Pakistan, the Ionospheric Research Station (IRS) was established in Islamabad on the campus of the Quaid-i-Azam University. An upgraded version of the PIR (PIR-9B) was installed at IRS (Khan and Ara, 1993). The ionograms obtained from these ionosondes were scaled manually at that time, and the critical parameters were disseminated to radio broadcasters and HF users on a monthly basis. Data processing and parameter extraction was also done manually by trained technicians due to the unavailability of auto-scaling software. Therefore, the time consumed on data processing was a huge constraint. Moreover, data were recorded on magnetic tapes (later on compact discs) which had a high probability of data corruption. The transportation of tapes from remote observatories to the data processing centre in Karachi was also risky and caused delays with respect to the analysis.

Despite the challenges of that era, Pakistan ionospheric data (PID) bulletins were regularly issued to national broadcasting and defence agencies (Mehmud, 1989). These bulletins consisted of monthly hourly median values of the lowest frequency of vertical ionospheric reflections $(f$-min);

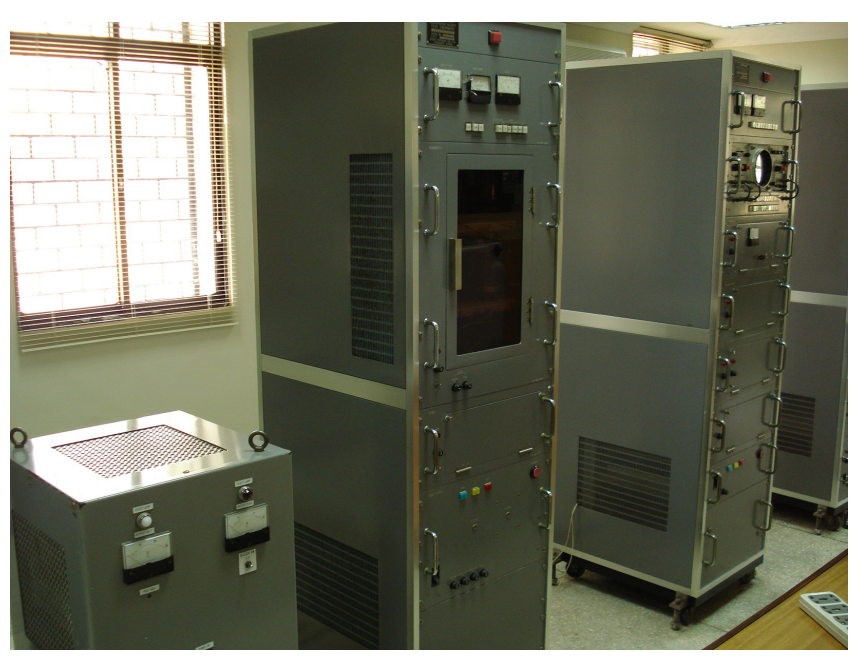

Figure 2. An image of the Panoramic Ionospheric Recorder-9 (PIR-9).

critical frequencies of the E, Es, $\mathrm{F} 1$ and $\mathrm{F} 2$ layers $(f o \mathrm{E}, f o \mathrm{Es}$, $f o \mathrm{~F} 1$ and $f o \mathrm{~F} 2$ respectively); the blanketing frequency of the Es layer ( $f b \mathrm{Es}$ ); and virtual heights of the E, Es, F and F2 layers ( $h^{\prime} \mathrm{E}, h^{\prime} \mathrm{Es}, h^{\prime} \mathrm{F}$ and $h^{\prime} \mathrm{F} 2$ respectively).

The earnest staff at the IR Division devised algorithms for maximum usable frequency (MUF) prediction circuits in the 1980s. MUF and FOT (frequency of optimum traffic) prediction charts were introduced in 1982 and were provided on a monthly, quarterly and seasonal basis comprising 1-hop, 2hop and 3-hop transmissions over 216 national and international HF circuits. With the introduction of HP9845B desk- 
Table 1. Time series expansion of ionospheric and geomagnetic observatories in Pakistan.

\begin{tabular}{lll}
\hline Year & Establishment of observatory & Geographic location \\
\hline 1953 & Geomagnetic observatory, Quetta (Qta) & $30.18^{\circ} \mathrm{N}, 67.00^{\circ} \mathrm{E}$ \\
1961 & Geomagnetic observatory, Gilgit (Gil) & $35.88^{\circ} \mathrm{N}, 74.46^{\circ} \mathrm{E}$ \\
1971 & Ionospheric station, Karachi (Khi) & $24.95^{\circ} \mathrm{N}, 67.14^{\circ} \mathrm{E}$ \\
1978 & Ionospheric Research Station, Islamabad (Isl) & $33.71^{\circ} \mathrm{N}, 73.06^{\circ} \mathrm{E}$ \\
1983 & Geomagnetic observatory, Karachi (Khi) & $24.95^{\circ} \mathrm{N}, 67.14^{\circ} \mathrm{E}$ \\
1987 & Space Applications and Research Station, Multan (Mul) & $30.15^{\circ} \mathrm{N}, 71.52^{\circ} \mathrm{E}$ \\
2008 & Geomagnetic observatory, Islamabad (Isl) & $33.71^{\circ} \mathrm{N}, 73.06^{\circ} \mathrm{E}$ \\
& Abdus Salam geomagnetic observatory and ionospheric station, Sonmiani (Son) $)^{*}$ & $25.42^{\circ} \mathrm{N}, 66.59^{\circ} \mathrm{E}$ \\
\hline
\end{tabular}

* Both shifted to Sonmiani from Karachi.

top computers at SUPARCO in the mid-1980s, an effort was made to automate MUF prediction codes using HP BASIC. However, these codes lacked compatibility with other systems, as the language and data storage modes were not supported by them. The team had to convert the codes into Fortran for further readability on all standard PCs (Hasan et al., 2002). The Fortran code used CCIR (Committee Consultative for Ionospheric Radiowave propagation) coefficients to calculate hourly median MUF and FOT values (Hasan et al., 2002). MUF values were then validated using ionosonde $f o \mathrm{~F} 2$ and $M(3000) \mathrm{F} 2$ (propagation factor) data from the stations.

The long gap after the PMD geomagnetic observatory installation was filled with the installation of a fluxgate magnetometer FM-100C in Karachi in March 1982. It had the ability to provide the $X, Y$ and $Z$ components of the localized geomagnetic field. Prior to the magnetometer installation, geomagnetic field variations were computed using a computer code based on the POGO 68/10 global geomagnetic field model (SUPARCO, 1984; available at SUPARCO library). The FM-100C was replaced by a Canadian Automatic Magnetic Observatory System-III (AMOS-III) in 1983 (Fig. 3). This observatory hosted a fluxgate magnetometer (FM-100C), a proton precession magnetometer (PPM-105) and a variometer (FM-157), acquiring data at a 1 min interval. The $X, Y$ and $Z$ components of the geomagnetic field and the total scalar field $F$ were calculated with a resolution of 0.4 and $0.1 \mathrm{nT}$ respectively. Geomagnetic storms were reported to the World Data Center in Boulder, Colorado, USA (SUPARCO, 1986; available at SUPARCO library). One of the geomagnetic storms reported by AMOS-III is shown in Fig. 4. SUPARCO has been sharing monthly geomagnetic data bulletins with national users since 1983 .

The most noteworthy progress during the 1980s was the expansion of the observation network in Pakistan. In 1987, a new ionospheric station, the Space Applications and Research Station (SPARS), was established on the Bahauddin Zakariya University Campus, Multan, with the aim of covering the central eastern part of the country. PIR-9 was moved from Karachi to Multan (Ameen and Ayub, 2008) and, in

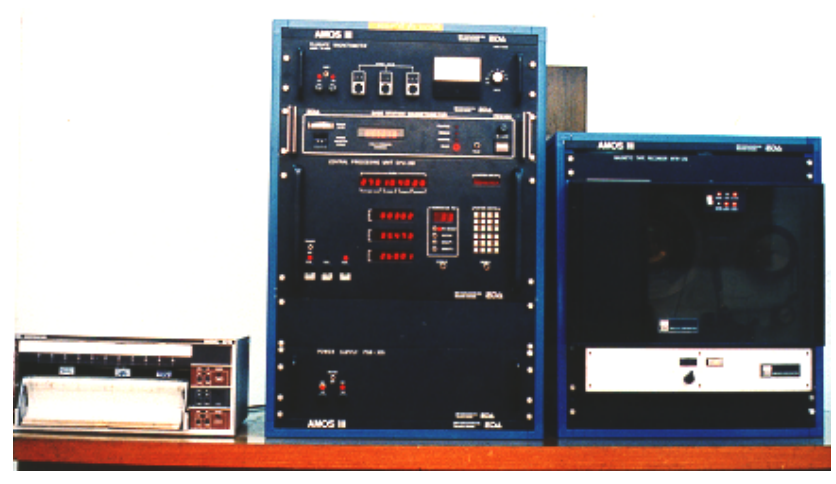

Figure 3. Automatic Magnetic Observatory System-III (AMOSIII).

the same year, an American Digisonde (DGS-256) was installed at Karachi (as shown in Fig. 5). The Islamabad station was also upgraded with a DGS-256 in 1992 (Khan and Ara, 1993). In comparison with the PIR-9 analogue sounder, the DGS-256 was able to provide data in real time (Ameen and Ayub, 2008). Alerts and warnings about adverse conditions were issued via fax to the national users. Propagation conditions affected mainly due to the presence of the sporadic $E$ (Es) layer, narrowing of the usable frequency bands (Fig. 6), sudden decreases in the ionospheric heights, ionospheric storms, radio blackouts and spread $F$ were promptly communicated to users throughout the 1980s. The readiness of services improved with the introduction of the latest equipment in the late 1980s and early 1990s. Table 2 shows the network of instruments that has been installed in Pakistan to date.

In the 2006-2007 financial year, the government of Pakistan approved the funds for a project proposed by SUPARCO. The project was aimed at upgrading the ionospheric and geomagnetic field monitoring capabilities in the country. This included the procurement of a Digisonde and magnetometers along with the establishment of a new geomagnetic observatory at Islamabad. Karachi geomagnetic observatory was upgraded with the installation of the International Network of Digital Geomagnetic Observatories (INDIGO) ob- 


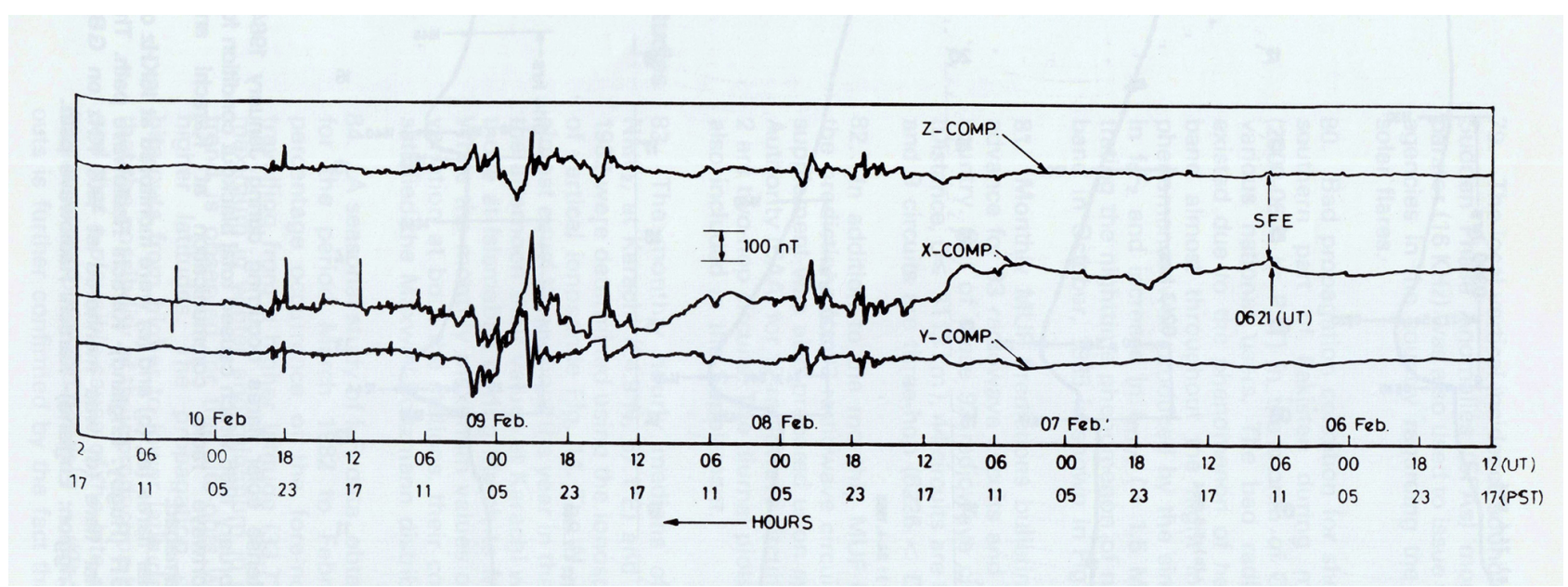

Figure 4. This figure shows a magnetic storm due to a solar flare effect (SFE) recorded by AMOS-III in February 1986. (Image credits: SUPARCO, 1986; available at SUPARCO library.)

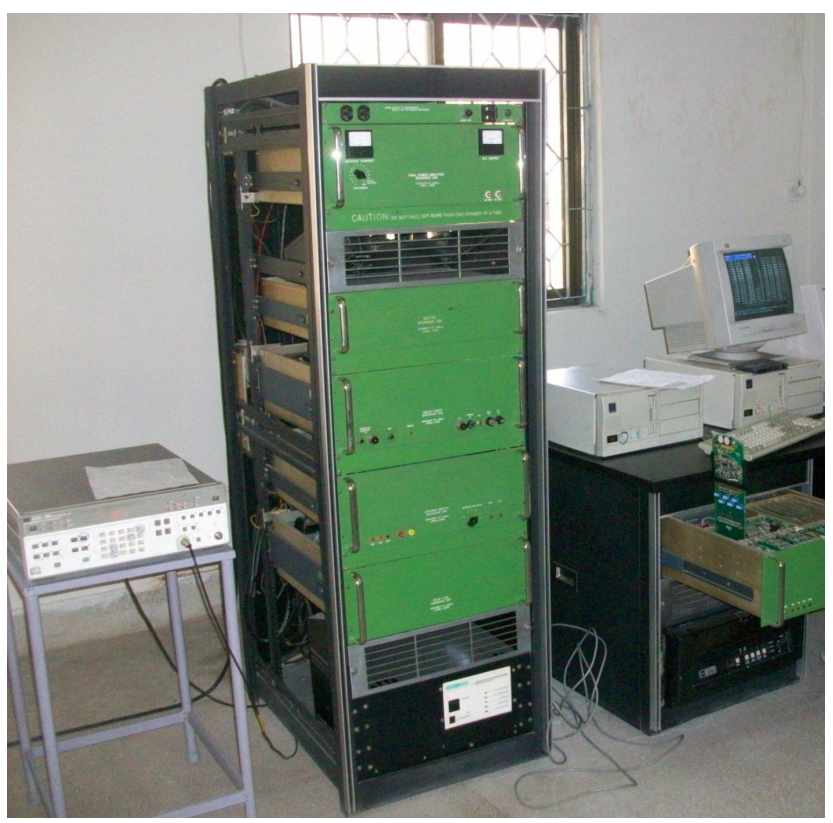

Figure 5. A view of the DGS-256 installed at the Karachi Ionospheric Station (KIS).

servation system in 2007 (Fig. 7). The INDIGO project is a joint effort by the BGS and the Royal Meteorological Institute (IRM) of Belgium and provides magnetometers to developing nations (Thomson, 2017). This observatory hosted an EDA fluxgate magnetometer (105B). The same observatory was moved to Sonmiani due to increased urbanization in 2008. Under the development project, the new observatory at Sonmiani was equipped with a complete observation system comprising a magnetometer from GEM systems known as delta inclination delta declination (dIdD), a FLV-1A triaxial fluxgate variometer (LAMA) from IRM (Belgium) and a DI-
Flux Theodolite (Zeiss THEO 010) magnetometer procured from MinGeo Ltd. In the same year, the DGS-256 installed at Karachi was moved to Sonmiani, and the manual ionosonde (PIR-9) at Multan was replaced by an automated DPS-4 (digital portable sounder) (Ameen and Ayub, 2008). A new geomagnetic observatory was also set up at Islamabad in 2008 , comprising the same set of instruments as that installed at Sonmiani. SUPARCO arranged the first International Workshop on Geomagnetic Observatories and their Applications in April 2012 in collaboration with IRM, the Inter-Islamic Network on Space Sciences and Technology (ISNET) and the National Centre for Physics (NCP). The workshop was attended by members from Organization of Islamic Conference (OIC) countries and local participants.

\section{The contemporary space weather era}

When SUPARCO researchers attended the XIIIth IAGA (International Association of Geomagnetism and Aeronomy) Workshop held in Boulder, CO, USA, in 2008, they took advantage of the unique opportunity to make a contribution regarding taking absolute geomagnetic measurements using the Tavistock-V042717. A presentation was given on the topic of "Geomagnetic Activities of Pakistan" (Ashfaque et al., 2008). The participants also visited the Space Weather Prediction Center (SWPC), which is a part of the National Oceanic and Atmospheric Administration (NOAA; Love, 2008). This experience, when shared with the senior administration upon their return, received much appreciation, and the idea of creating a complete space weather network was conceived. SUPARCO had been active in this field for quite some years; therefore, a conversion to a centralized space weather centre was impending. This idea was reinforced in 2012 when one researcher returned from a masters programme specializing in ionospheric physics with hands- 
Table 2. Space weather instruments operated in Pakistan to date. Please see Table 1 for the location abbreviations.

\begin{tabular}{|c|c|c|c|c|c|}
\hline Category & Instrument & Location & $\begin{array}{l}\text { Duration } \\
\text { operated }\end{array}$ & Observed parameters & $\begin{array}{l}\text { Sampling } \\
\text { rate }\end{array}$ \\
\hline \multirow{8}{*}{ Ionosondes } & Mark-11 & \multirow{3}{*}{ Khi } & $1971-1975$ & \multirow{8}{*}{$\begin{array}{l}f \text {-min, } f o \mathrm{E}, f o \mathrm{Es}, f b \mathrm{Es}, f o \mathrm{~F} 1 \\
f o \mathrm{~F} 2, h^{\prime} \mathrm{E}, h^{\prime} \mathrm{Es}, h^{\prime} \mathrm{F} \text { and } h^{\prime} \mathrm{F} 2\end{array}$} & \multirow{8}{*}{$15 \mathrm{~min}$} \\
\hline & PIR-9 & & $1975-1987$ & & \\
\hline & DGS-256 & & $1987-2008$ & & \\
\hline & PIR-9B & \multirow{2}{*}{ Isl } & 1978-1992 & & \\
\hline & DGS-256 & & 1992-2016 & & \\
\hline & PIR-9 & \multirow{2}{*}{ Mul } & 1987-2008 & & \\
\hline & DPS-4 & & 2008-2014 & & \\
\hline & TYC-1 & Son & 2017 to date & & \\
\hline \multirow{12}{*}{ Magnetometers } & Quartz & \multirow{3}{*}{ Qta } & \multirow{3}{*}{$1953-1990$} & \multirow{6}{*}{$H, D, Z$ and $F$} & \multirow{6}{*}{$1 \mathrm{~min}$} \\
\hline & Balance zero & & & & \\
\hline & Unimag proton & & & & \\
\hline & BMZ-240 & \multirow{3}{*}{ Gil } & 1964-1994 & & \\
\hline & BMZ-238 & & 1965-1994 & & \\
\hline & QHM-503 & & 1965-2015 & & \\
\hline & PPM-105 & \multirow{2}{*}{ Khi } & $1983-2007$ & $X, Y, Z$ and $F$ & $1 \mathrm{~min}$ \\
\hline & Tavistock & & 2007-2009 & Inclination and declination & - \\
\hline & dIdD & \multirow{2}{*}{ Isl/Son } & \multirow{2}{*}{2008 to date } & Geomagnetic field $F$ & $2.5 \mathrm{~s}$ \\
\hline & Zeiss THEO 010 & & & \multirow{2}{*}{ Inclination and declination } & \multirow{2}{*}{-} \\
\hline & FLM-4 Flux Theo & Isl/Son & 2016 to date & & \\
\hline & GSM - 19T & Mobile & 2013 to date & $F$ field & $3 \mathrm{~s}$ \\
\hline \multirow{5}{*}{ Variometers } & Ruska & Qta & 1953-1990 & \multirow{2}{*}{$H, D, Z$ and $F$} & \multirow{2}{*}{$1 \mathrm{~min}$} \\
\hline & GV3 & Gil & 1967-1998 & & \\
\hline & FM-157 & \multirow{2}{*}{ Khi } & $1983-2007$ & $X, Y, Z$ and $F$ & \multirow{2}{*}{$1 \mathrm{~min}$} \\
\hline & INDIGO & & $2007-2008$ & $X, Y$ and $Z$ & \\
\hline & LAMA & Isl/Son & 2008 to date & $H, D$ and $Z$ & $5 \mathrm{~s}$ \\
\hline \multirow{2}{*}{ Radio burst monitors } & \multirow{2}{*}{ CALLISTO } & Son & 2014 to date & \multirow{2}{*}{ Spectrogram (FITS) file } & \multirow{2}{*}{$15 \mathrm{~min}$} \\
\hline & & Mul & 2015 to date & & \\
\hline Solar flare monitors & SID monitor & Isl/Son/Mul & 2012 to date & Changes in very low frequency signal strength & $5 \mathrm{~s}$ \\
\hline \multirow[t]{2}{*}{ Scintillation monitors } & \multirow[t]{2}{*}{ ISM } & Son/Qta & 2014 to date & \multirow{2}{*}{$\mathrm{TEC}, S_{4}, \sigma_{\phi}$} & \multirow{2}{*}{$15 \mathrm{~s}$} \\
\hline & & Mul & 2015 to date & & \\
\hline
\end{tabular}

on training at the Space Weather Services (then called the Ionospheric Prediction Services), Australia. The very next year, the Sonmiani geomagnetic observatory received International Real-time Magnetic Observatory Network (INTERMAGNET) certification and obtained the status of a fully operating INTERMAGNET Magnetic Observatory (IMO) (INTERMAGNET, 2020b).

At the time, Pakistan was advancing its space technology programme with PAKSAT-1R, a communication satellite, which had already been in orbit since August 2011 (PAKSAT, 2020). The design and development of upcoming satellites was also in progress. Pakistan's first remote sensing and technology evaluation satellites, PRSS-1 and PAK TES-1A respectively, were launched in July 2018 (Murtaza and Khan, 2020). In order to protect ground-based and spaceborne technological assets and to achieve optimum performance from these instruments, a dire need was felt to upgrade space weather monitoring and forecasting. This led to the formulation of ways to transfer manual data to real time in order to preserve its reliability. Thus, at this time, a genuine need was felt to establish a state-of-the-art space weather monitoring facility to function as a central data processing hub that was interconnected with remote data acquisition sites. Accessing data in real time was envisaged in the national space plan; upon implementation of an online system, it was further recommended to that a dedicated centre, based on the model of 


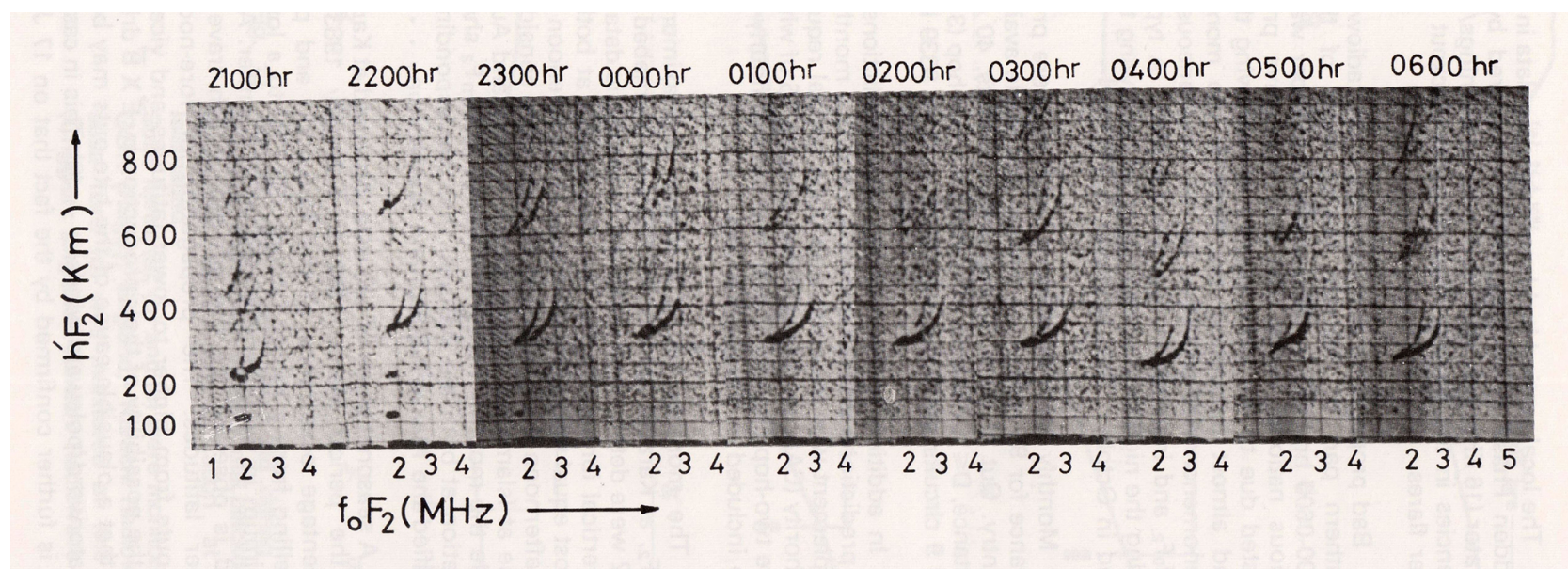

Figure 6. A composite image of an ionogram showing narrowing in the frequency band on 1 and 2 October 1985. (Image credits: SUPARCO, 1986; available at SUPARCO library.)

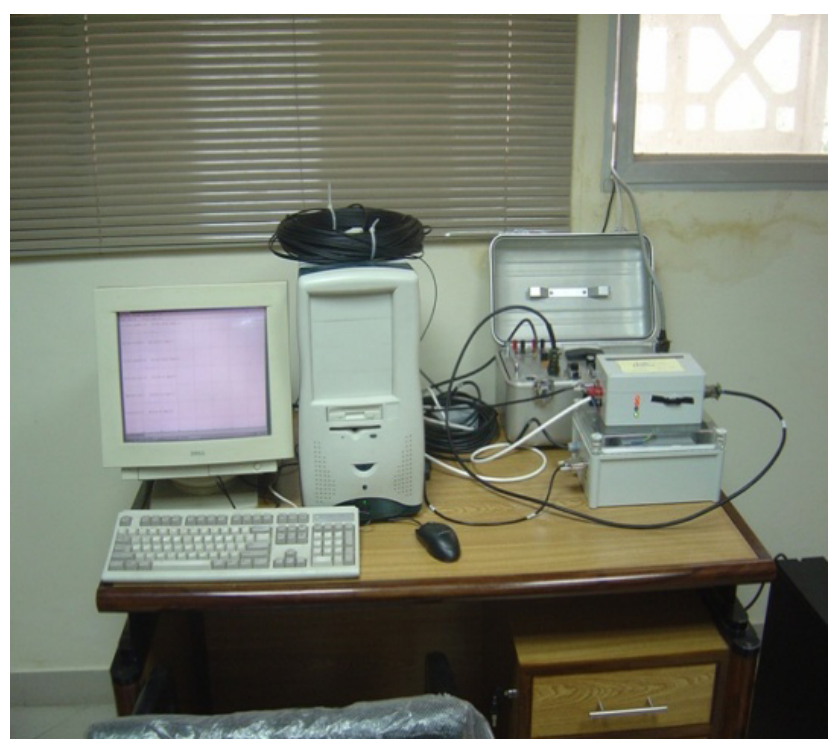

Figure 7. The INDIGO System.

pre-existing facilities in developing countries, be established in Pakistan.

The "Establishment of Space Weather Monitoring Centre" project was approved as a development project by the government of Pakistan in December 2012 and was formally initiated in April 2013. The project began with the aim of complementing Pakistan's vision of advancement in space research.

The project initially involved the following:

- upgradation of existing instruments and the installation of new instruments to monitor diverse space weather phenomena;
- deployment of a state-of-the-art network architecture to securely link various remote stations with the data centre via a virtual private network (VPN) in order to communicate space weather information to users via a web portal and to archive the data in a full-fledged anchored database;

- enhancement of the capacity of the technical staff to keep abreast of current advances in the field of space weather monitoring and forecasting;

- establishment of a central processing facility.

The facility was named the Pakistan Space Weather Centre (PSWC) when it was officially inaugurated on $20 \mathrm{Au}-$ gust 2018.

\subsection{New installations and upgradation}

In order to meet the contemporary requirements of groundbased monitoring of solar activity, new antennas and sensors were installed during the period from 2012 to 2014 to monitor space weather effects in real time. Under the United Nations (UN) International Space Weather Initiative (ISWI) programme, SUPARCO received three sudden ionospheric disturbance (SID) monitors (see Fig. 8) which were installed at the stations in Islamabad, Multan and Sonmiani respectively. The SID was developed by Stanford University, USA, under funding from the Center for Integrated Space Weather Modeling (CISM).

For the monitoring of solar radio bursts, SUPARCO procured two CALLISTO (compound astronomical lowfrequency low-cost instrument for spectroscopy and transportable observatory) receivers from Reeve Observatory, USA. A CALLISTO instrument was installed at Sonmiani and Multan in November 2014 and February 2015 respectively. 


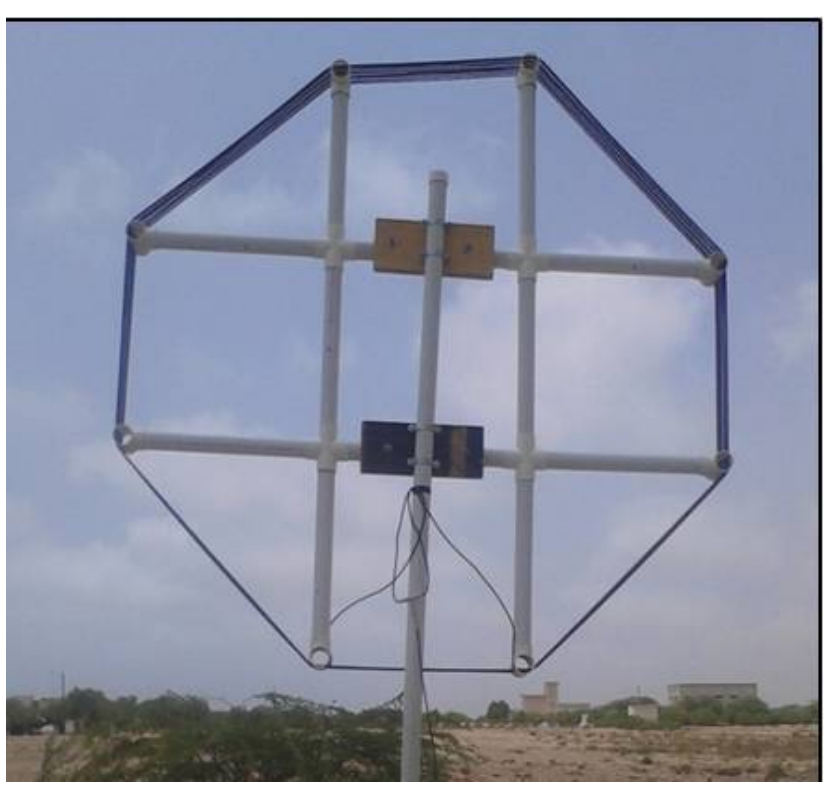

Figure 8. Antenna of the sudden ionospheric disturbance monitor installed at Sonmiani.

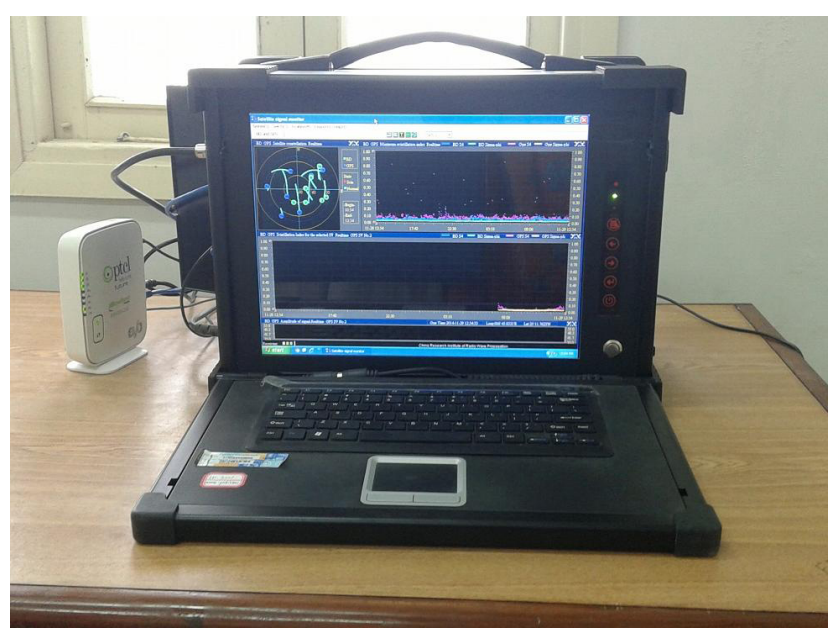

Figure 9. Ionospheric scintillation monitor. PC with "Satellite Signal Monitor" software installed.

A further three ionospheric scintillation monitors (ISM), also known as total electron content (TEC) receivers, were installed during the period from 2013 to 2015 (Figs. 9, 10). One installation took place as part of the Asia-pacific Space Cooperation Organization (APSCO) project named "Atmospheric Effects on Ionospheric Modeling through Study of Radio Wave Propagation and Solar Activity" undertaken in collaboration with the China Research Institute of Radiowave Propagation (CRIRP). The other two were installed in Quetta and Multan in collaboration with the Centre for Earthquake Studies (CES), NCP, Islamabad.

In May 2017, CRIRP agreed to provide a new ionosonde to SUPARCO in the framework of APSCO. Before the equip-

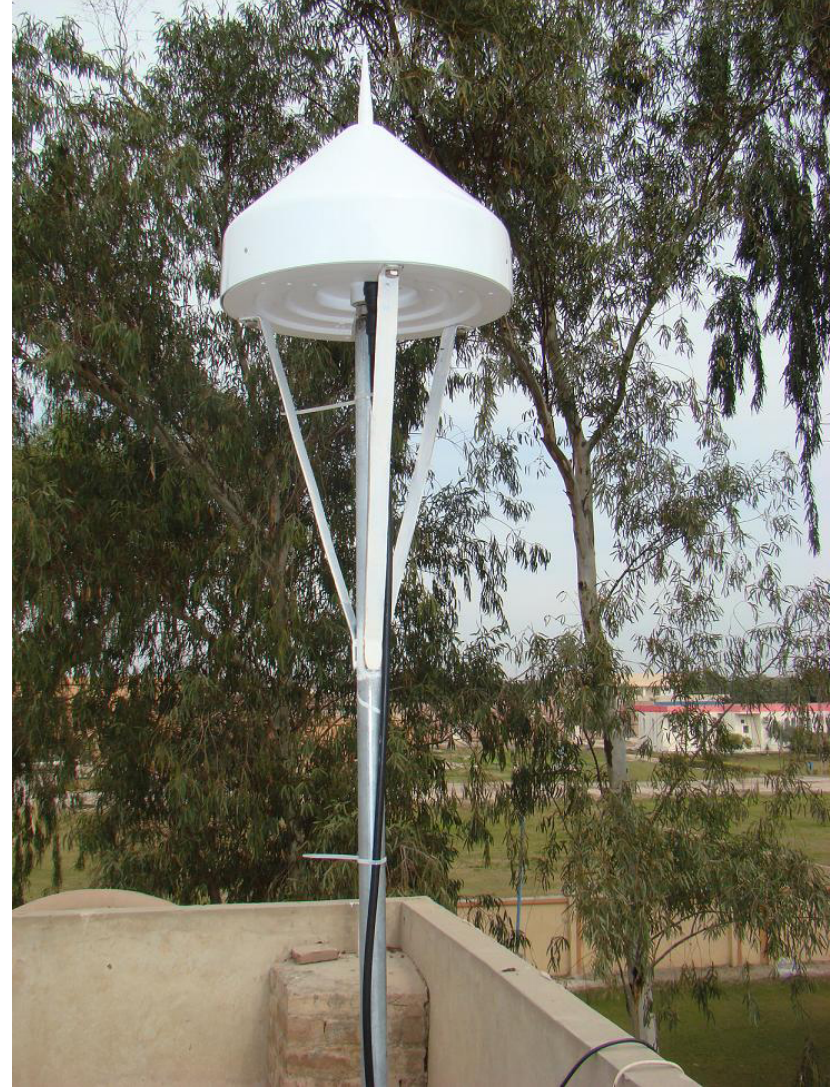

Figure 10. Global Navigation Satellite System (GNSS) signal receiving antenna at Multan.

ment deployment, the antenna site was prepared by erecting one $50 \mathrm{~m}$ high and four $12 \mathrm{~m}$ high masts for transmitting and receiving antennas respectively (Fig. 11). A team of engineers from CRIRP visited SUPARCO in September 2017 to assist SUPARCO officials with the installation of the ionosonde and to train technical staff on safe ionosonde operation, maintenance and data handling (Fig. 12). Table 2 provides more details regarding the instruments installed during the project.

\subsection{Development of an integrated networking system for real-time data acquisition}

The prime purpose of the establishment of the PSWC was met when a state-of-the-art networking system was furnished via a secure network, integrating available instruments from all remote data acquisition sites. This central hub now hosts the main data server and processing and archiving centre, providing real-time space weather visibility in the country. A detailed system architecture showing various components of the system is depicted in Fig. 13. 


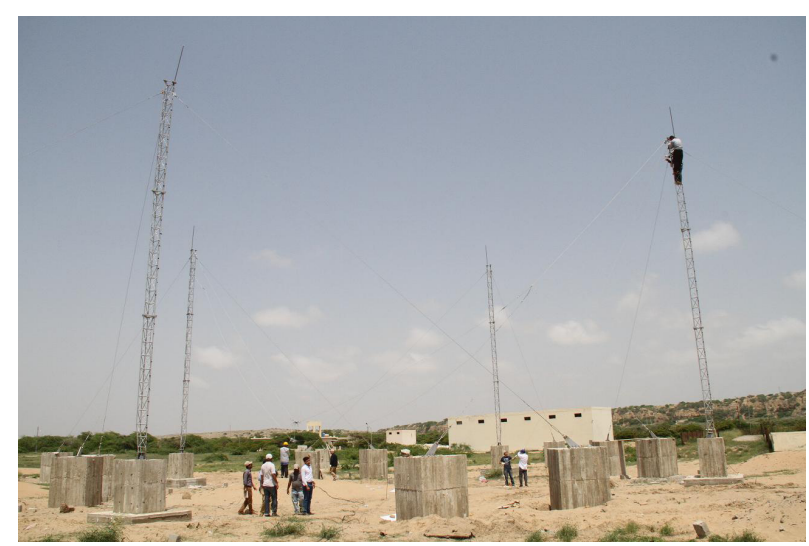

Figure 11. A view of the ionosonde antenna site at Sonmiani.

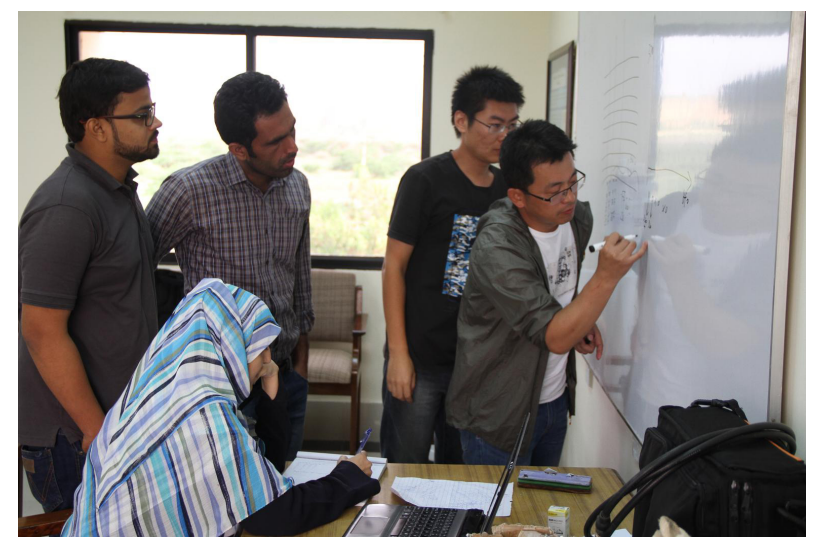

Figure 12. An image captured during one of the training sessions.

\subsection{Capacity building efforts and hosting of international workshops}

The technical staff were considered a vital segment during the establishment of the space weather centre regarding the achievement of the ultimate goals of the project. Keeping this in mind, researchers from SUPARCO were given the opportunity to attend workshops and conferences relevant to the space weather domain. In 2014, two research studies pertaining to the space science domain were presented from SUPARCO at the 40th COSPAR (Committee on Space Research) Scientific Assembly held in Moscow, Russia (Ameen et al., 2014 and Talha et al., 2014).

SUPARCO is an associate member of Asia-Oceania Space Weather Alliance (AOSWA). While attending the " 4 th AOSWA workshop" held on Jeju Island, South Korea, in October 2016, the director of Space Science at SUPARCO discussed a training proposal with the director of the Korean Space Weather Center (KSWC). The proposal was accepted by KSWC and, as a result, four researchers were sent to KSWC (Fig. 14) to acquire dedicated training on space weather forecasting and modelling. The following significant learning outcomes resulted from the training:
- an understanding of the methodologies used to predict radio blackouts, solar radiation storms and geomagnetic storms;

- comprehension of the URSI (International Union of Radio Science) gram code and estimation method for forecasting communication accuracy;

- an understanding of techniques used to classify sunspot types;

- experience with the WSA-ENLIL (Wang-SheeleyArge) and interplanetary scintillation (IPS) models to predict the influence of solar wind and to estimate the arrival time of coronal mass ejections (CMEs) and high speed streams after the passage of co-rotating interaction regions (CIRs);

- experience with the calculation of space radiation exposure dose on polar air routes using the DREAM (Dynamic Radiation Environment Assimilation) (Reeves et al., 2012) model (Safety during Aviation Flight Environment, SAFE, programme at KSWC);

- an understanding of the integration of real-time data from ground-based instruments into space weather models to generate forecasts in real time.

Within a year of the establishment of the PSWC, the SWM Division was able to provide a platform for institutes and space agencies of Islamic countries to develop capacity in the field of geomagnetism and ionosphere research. After successfully hosting the first workshop in 2012, the "2nd International Workshop on Geomagnetism and Ionosphere" was held in November 2018 in Sonmiani. The workshop was conducted by SUPARCO in collaboration with ISNET and IRM. A total of 38 participants including 11 from Organization of Islamic Conference (OIC) member countries were given training on geomagnetic observatory operation and ionospheric data analysis (Fig. 15). Experts from IRM, led by Jean Rasson (head of department) of Geophysics Services and Research, provided training to scientists and officials from space science departments of OIC member countries in order to promote the installation of new geomagnetic observatories and ionospheric monitoring stations by their respective organizations.

SUPARCO has conducted joint research projects with undergraduate and postgraduate students, utilizing local data, as part of the SUPARCO-Academia collaboration programme. Several batches of students have completed such projects under the supervision of SUPARCO researchers since the establishment of the centre. Some of these students availed opportunities to attend space weather workshops at the Abdus Salam International Centre for Theoretical Physics (ICTP) in 2019 and presented their research (Ameen, 2020). The space weather datasets acquired by SUPARCO have been reported in the form of publications in reputable journals. Publications 

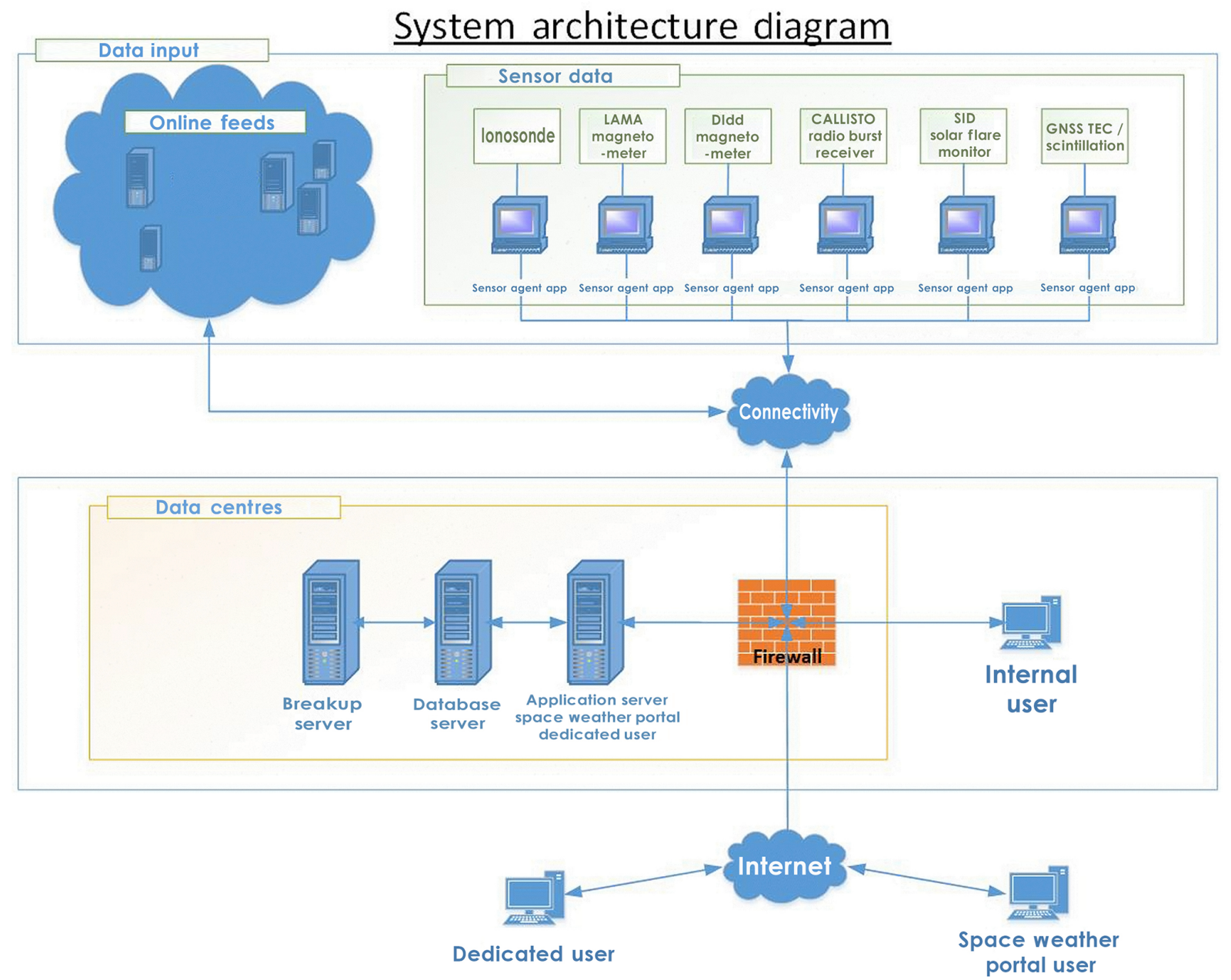

Figure 13. Overview of the integrated monitoring system developed as a part of the project.

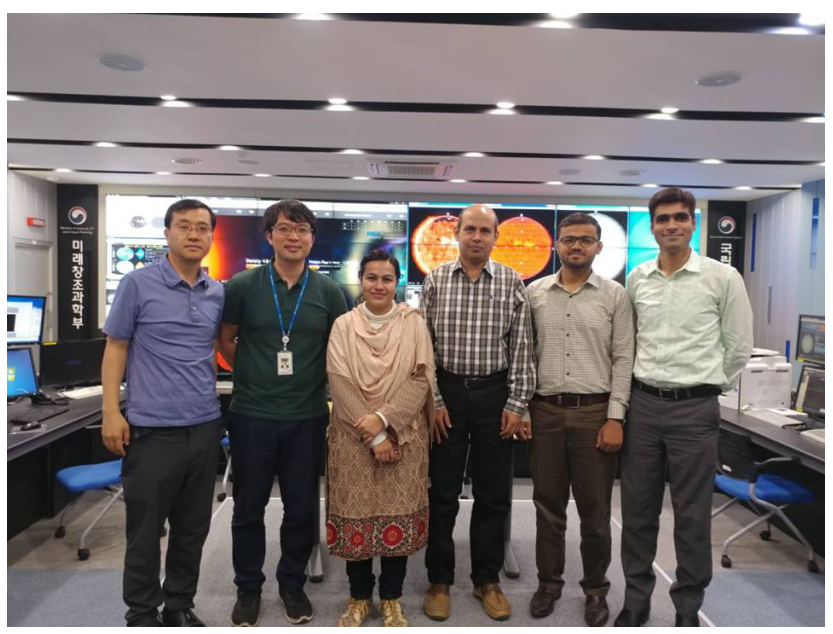

Figure 14. Four SUPARCO officials visited the Korean Space Weather Center to learn about space weather monitoring practices carried out in South Korea.

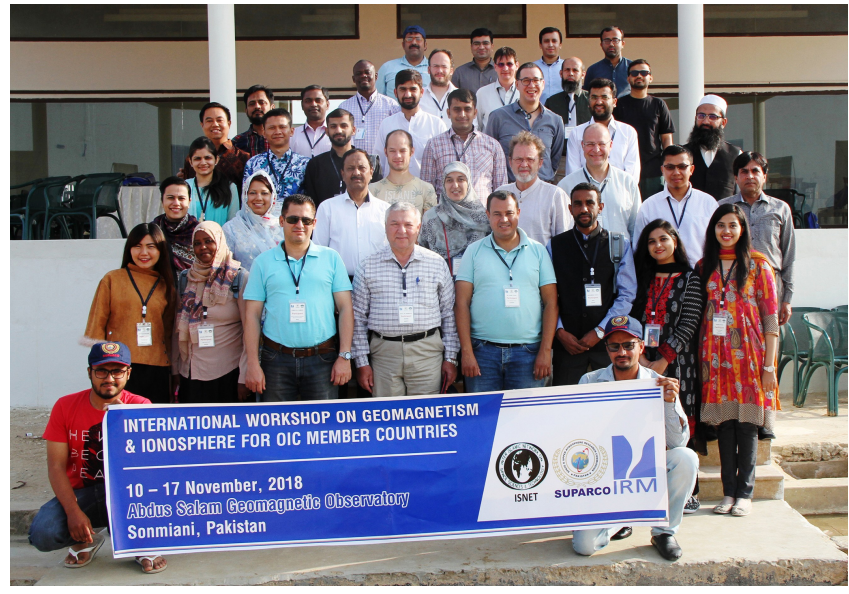

Figure 15. Participants of the workshop. 


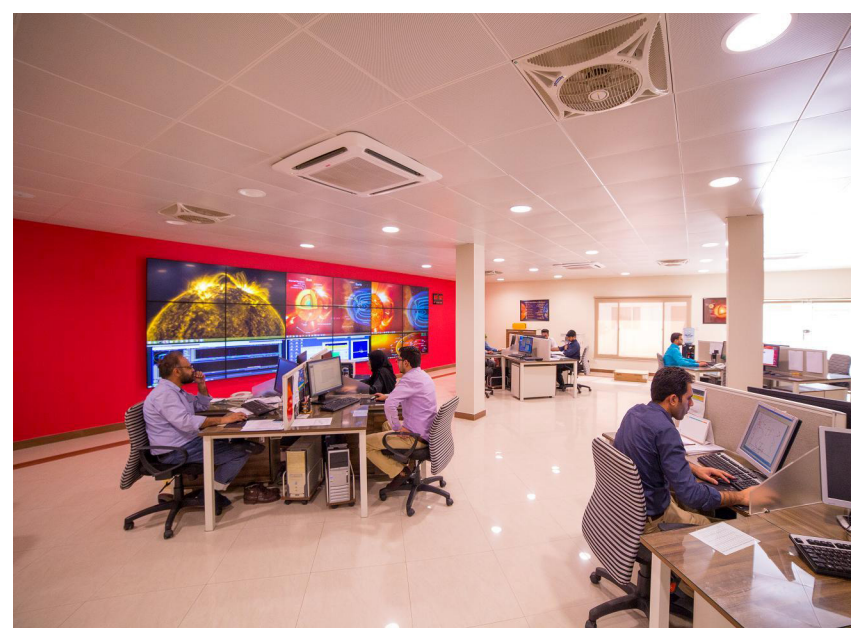

Figure 16. An image from the Pakistan Space Weather Centre.

utilizing geomagnetic data include Rahim et al. (2013) and Rahim and Kumbher (2016). Articles based upon comparing ionospheric data with locally developed and international models include Ameen et al. (2018, 2019a, b) and Talha et al. (2019a, b).

\section{Data products and services}

Since the establishment of the centralized data processing facility at the PSWC (Fig. 16), the acquisition, processing, archiving and dissemination of space weather data has been taking place round the clock. In the post-project phase, the following activities, in connection with core objectives of the project, are being carried out:

1. the Sun-Earth connection is being investigated regularly with the help of real-time data from upgraded equipment;

2. Real-time alerts and warnings are being provided to space weather users;

3. a daily space weather summary, containing services regarding ionospheric, geomagnetic and solar data, is updated on the SUPARCO official website (SUPARCO, 2020);

4. total geomagnetic field and component values recorded at Sonmiani observatory are shared with INTERMAGNET (INTERMAGNET, 2020a);

5. monthly ionospheric data bulletins recorded from local ionosondes and monthly geomagnetic bulletins from observatories in Pakistan are dispatched to the HF and wireless operators, the aviation industry, telecommunication companies and the Survey of Pakistan.

\section{Conclusions}

Pakistan has a rich history of ground-based monitoring of the ionosphere and geomagnetic field spanning the past 5 decades. However, the growing need for these data with time demand the fulfillment of the present modalities of space weather monitoring and forecasting. In the present realm, Pakistan's space weather monitoring and forecasting programme will elevate in collaboration with regional cooperation fora like APSCO and AOSWA. This will lead SUPARCO from research to operations (R2O) in the domain of space weather. Since its commissioning, SUPARCO, as the national space agency of Pakistan, has been mandated to carry out research and development activities in the domain of space sciences and applications in accordance with Pakistan's Space Vision 2040. With the launch of several Earth observation and telecommunication satellites being envisaged, the PSWC will safeguard and ensure the safe launch and smooth operations of these devices. In the coming years, Pakistan plans to enter the mainstream international space weather community by formulating and documenting a space policy unanimously with all national stake holders. In addition, the preparation of a skilled workforce in the framework of the SUPARCO-Academia collaboration will allow SUPARCO's space weather legacy to thrive and prosper. Further, in order to collaborate with the international scientific community to enhance capacity in this intricate field, Pakistan intends to become one of the Regional Warning Centers (RWCs) of the International Space Environment Services (ISES).

Data availability. No formal datasets were used in this research.

Author contributions. All authors contributed to the project. AT prepared the paper with contributions from all co-authors.

Competing interests. The authors declare that they have no conflict of interest.

Special issue statement. This article is part of the special issue "History of regional warning centers". It is not associated with a conference.

Acknowledgements. The authors are grateful to the three anonymous reviewers for their valuable comments. We would also like to thank the present and ex-staff of SUPARCO, who helped the authors in preparation of this paper. Afnan Tahir would like to thank Nabeel Ahmed for assistance with gathering data and designing Table 2. Special thanks are due to the topical editor, Phil Wilkinson, for his valuable suggestions and recommendations that helped to improve the paper. 
Review statement. This paper was edited by Philip Wilkinson and reviewed by three anonymous referees.

\section{References}

Ameen, M. A.: Space Weather Monitoring in Pakistan, available at: https://www.unoosa.org/documents/pdf/copuos/stsc/2020/ tech-27E.pdf, last access: 31 May 2020.

Ameen, M. A. and Ayub, M.: DPS-4 Installation at Multan, Pakistan, Tech. Rep. 69, SWS, Bureau of Meteorology, Australia, available at: https://www.sws.bom.gov.au/IPSHosted/ INAG/web-69/index.html (last access: 20 March 2020), 2008.

Ameen, M. A., Raza, K., and Ayub, M.: Variation of NmF2 and hmF2 deduced from DPS-4 over Multan (Pakistan) and their comparisons with IRI-2007 \& IRI-2012 during the deep solar minimum between 23rd and 24th solar cycles, in: 40th COSPAR Scientific Assembly, Vol. 40, C4.1-22-14, available at: https://ui.adsabs.harvard.edu/abs/2014cosp...40E..83A (last access: 15 March 2020), provided by the SAO/NASA Astrophysics Data System, 2014.

Ameen, M. A., Khursheed, H., Jabbar, M. A., Ali, M. S., and Chishtie, F.: Variation of $\mathrm{hmF} 2$ and $\mathrm{NmF} 2$ deduced from DPS-4 over Multan (Pakistan) and their comparisons with IRI-2012 \& IRI-2016 during the deep solar minimum between cycles 23 \& 24, Adv. Space Res., 61, 1726-1735, https://doi.org/10.1016/j.asr.2018.01.043, 2018.

Ameen, M. A., Jabbar, M. A., Murtaza, G., Chishtie, F., $\mathrm{Xu}$, T., Zhen, W., Atiq, M., and Ali, M. S.: Single station modelling and comparison with ionosonde foF2 over Karachi from 1983 to 2007, Adv. Space Res., 64, 2104-2113, https://doi.org/10.1016/j.asr.2019.06.003, 2019a.

Ameen, M. A., Jabbar, M. A., Yu, X., Zhen, W., Murtaza, G., Chishtie, F., Khursheed, H., and Atiq, M.: Comparison of Ionospheric Total Electron Content (TEC) over Sonmiani (Pakistan) with NeQuick-2 and IRI-2012 during July 2014-June 2015, Adv. Space Res., 63, 1882-1891, https://doi.org/10.1016/j.asr.2018.09.017, 2019b.

Ashfaque, M., Murtaza, G., Rasson, J. L., and Turbitt, C.: Geomagnetic Activities in Pakistan since 2006 - to date, in: Proceedings of the XIIIth IAGA Workshop on Geomagnetic Observatory Instruments, Data Acquisition, and Processing, U.S. Geological Survey, Boulder and Golden, Colorado, USA, available at: https://pubs.usgs.gov/of/2009/1226/pdf/OF09-1226.pdf (last access: 10 April 2020), 146-153, 2008.

Hasan, M. W., Iqbal, S., and Ansari, A.: Prediction of Maximum Usable Frequency (MUF)/OPTIMUM Traffic Frequency (FOT) For Single And Multi-Hop Circuits, in: Proceedings of the National Seminar on Atmospheric and Ionospheric Physics, SUPARCO, Karachi, Pakistan, 9-12, 2002.

INTERMAGNET: Data, available at: https://www.intermagnet.org/ index-eng.php (last access: 12 March 2020), 2020a.

INTERMAGNET: Observatories (IMOs), available at: https://www.intermagnet.org/imos/imos-list/imos-details-eng. php?iaga_code=SON (last access: 12 March 2020), 2020b.

Khan, Z. M. and Ara, H.: Ionosonde Network in Pakistan, Tech. Rep., available at: https://www.sws.bom.gov.au/ IPSHosted/INAG/pdf-i/inag59i.pdf (last access: 10 December 2019), 1993.
Love, J. J.: Proceedings of the XIIIthIAGA Workshop on geomagnetic observatory instruments, data acquisition, and processing, Open-File Report, U.S. Geological Survey, Boulder and Golden, Colorado, USA, available at: https://pubs.usgs.gov/of/ 2009/1226/pdf/OF09-1226.pdf (last access: 5 February 2020), 2008.

Mehmud, S.: Pakistan's space programme, Space Policy, 5, 217226, https://doi.org/10.1016/0265-9646(89)90088-X, 1989.

Murtaza, H. and Khan, A.: Pakistan Space Activities, in: Handbook of Space Security, Springer International Publishing, Cham, 116, https://doi.org/10.1007/978-3-030-22786-9_79-1, 2020.

Nicolet, M.: The International Geophysical Year, Nature, 180, 7-10, https://doi.org/10.1038/180007a0, 1957.

PAKSAT: PAKSAT-1R, available at: https://www.paksat.com.pk/, last access: 28 May 2020.

Rahim, Z. and Kumbher, A. S.: Solar daily variation at geomagnetic observatories in Pakistan, J. Atmos. Sol.-Terr. Phy., 140, 41-54, https://doi.org/10.1016/j.jastp.2016.01.016, 2016.

Rahim, Z., Ali, M. A., and Owais, A. M.: Validation of K-indices through comparative analysis for Sonmiani Geomagnetic Observatory, Pakistan, J. Atmos. Sol.-Terr. Phy., 102, 362-367, https://doi.org/10.1016/j.jastp.2013.05.002, 2013.

Reeves, G. D., Chen, Y., Cunningham, G. S., Friedel, R. W. H., Henderson, M. G., Jordanova, V. K., Koller, J., Morley, S. K., Thomsen, M. F., and Zaharia, S.: Dynamic Radiation Environment Assimilation Model: DREAM: DYNAMIC RADIATION ENVIRONMENT ASSIMILATION MODEL, Space Weather, 10, 3, https://doi.org/10.1029/2011SW000729, 2012.

SUPARCO: Space Research in Pakistan, 1984: a Report to COSPAR Twenty-fifth meeting, Graz, Austria, Tech. Rep., SUPARCO, Graz, Austria, 59 pp., 1984.

SUPARCO: Space Research in Pakistan, 1986: a report to COSPAR Twenty-sixth meeting, Toulouse, France, Tech. Rep., SUPARCO, Toulouse, France, 39 pp., 1986.

SUPARCO: Daily Space Weather Summary, available at: http:// suparco.gov.pk/, last access: 31 May 2020.

Talha, M., Nilsson, H., and Stenberg, G.: Precipitation of solar wind ions in the venusian upper atmosphere, an aspera- 4 investigation, in: 40th COSPAR Scientific Assembly, 40, B0.7-16-14, availabe at: https://ui.adsabs.harvard.edu/abs/2014cosp...40E3281T (last access: 31 May 2020), provided by the SAO/NASA Astrophysics Data System, 2014.

Talha, M., Ahmed, N., Ali, M. M., and Murtaza, G.: Variability of $\mathrm{NmF} 2$ during solar minima at the Equatorial Ionization Anomaly crest region, Adv. Space Res., 64, 2321-2330, https://doi.org/10.1016/j.asr.2019.09.014, 2019a.

Talha, M., Ahmed, N., and Murtaza, G.: Study the behavior of the ionospheric frequencies at Karachi during three consecutive solar minima of cycle $21,22 \& 23$ and their comparison with IRI-2016, Adv. Space Res., 63, 1905-1913, https://doi.org/10.1016/j.asr.2018.09.003, 2019b.

Thomson, A.: Geomagnetism Review 2016, Open Report OR/17/043, British Geological Survey, available at: https://geomag.bgs.ac.uk/documents/reviews/Geomagnetism_ Review_2016.pdf (last access: 12 December 2019), 2017. 